\title{
The dependence of upper ocean gyres on wind and buoyancy forcing
}

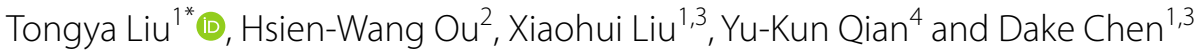

\begin{abstract}
A series of numerical simulations with different forcing conditions are carried out, to investigate the roles played by buoyancy and wind forcing on the upper ocean gyres, and to contrast the laminar and eddying regimes. Model experiments show that the buoyancy-driven eastward geostrophic flow tends to suppress the formation of the winddriven subpolar gyre, but the northward eddy heat transport can homogenize the subpolar water and reduce the meridional temperature gradient by about two-third, thus counteracting the buoyancy effect and saving the subpolar gyre. For the subtropical gyre, its transport is enhanced by eddy mixing, and the role of buoyancy forcing is very sensitive to the choice of diapycnal diffusivity. Our results suggest that eddy effects must be considered in the dynamics of the subpolar gyre, and vertical diffusivity should be selected carefully in simulating the basin-wide circulations.
\end{abstract}

Keywords: Wind forcing, Buoyancy forcing, Eddy mixing, Double gyres, Upper-ocean circulations

\section{Introduction}

The general ocean circulation is a great conveyor for water mass, heat, and tracers, playing a fundamental role in the global climate system (Ganachaud and Wunsch 2000). Wind stress (momentum flux) and buoyancy forcing (heat and salinity flux) at the ocean surface are the primary drivers of the general ocean circulation (Ferrari and Wunsch 2009; Stewart et al. 2014), whose upper branches (especially the subtropical and subpolar gyres) have been the major focus of physical oceanography. However, the relative contributions of wind and buoyancy forcing to the generation and maintenance of these gyres are still being debated, which motivates us to re-examine the coupled dynamics of the wind- and buoyancy-driven circulations.

Classic circulation theories based on the Sverdrup (1947) balance mainly focus on the large-scale circulation in a homogeneous ocean forced by the wind whereby the interior Sverdrup transport is closed by a western

\footnotetext{
*Correspondence: liutongya@sio.org.cn

${ }^{1}$ State Key Laboratory of Satellite Ocean Environment Dynamics, Second Institute of Oceanography, Ministry of Natural Resources, Hangzhou, Zhejiang, China

Full list of author information is available at the end of the article
}

boundary current (Stommel 1948; Munk 1950). The negative wind stress curl in the subtropics induces an Ekman downwelling and an associated anticyclonic gyre, while the opposite occurs in the subpolar region (applying to the northern hemisphere). In the subsequent decades, the wind-driven circulation theories have made remarkable progress, including the ventilated thermocline theory (Luyten et al. 1983), which resolves the vertical structure of the subtropical circulation, but its vertical integrated flow is still conformed to the Sverdrup relation.

Much observational evidence suggests that the laminar Sverdrup dynamics fail to describe some prominent features of the upper-ocean circulations. In the subtropics, Stommel (1965) and Qiu and Chen (2010) note that the main thermocline deepens almost linearly with the latitude, conflicting with that predicted by the Sverdrup dynamics. Colin de Verdière and Ollitrault (2016) point out that the Sverdrup dynamics produce a subtropical gyre that is about half as strong as the observed one. In the subpolar region, Gray and Riser (2014) suggest that nonlinear dynamics and complicated topography might cause the Sverdrup balance to be nullified.

To improve the theoretical framework of the largescale ocean circulation, previous studies have explored 
the roles of buoyancy flux in generating upper ocean gyres. Colin de Verdière (1988, 1989, referred to as CV89 hereafter) demonstrates that the buoyancy forcing alone could drive a basin-wide anticyclonic gyre above the thermocline, and that the wind-driven double-gyre pattern could be broken by the heat loss in the subpolar region where a broad eastward flow would occur in the upper layer. In the subtropics, Samelson and Vallis (1997) and Vallis (2000) note that there might be two distinct thermocline regimes, the ventilate thermocline and the internal thermocline, as outlined in their wind- and buoyancy-driven models. Recently, Gjermundsen et al. (2018) note that a global circulation forced only by buoyancy flux could reproduce many observed features. Unlike the single gyre driven by the buoyancy forcing in previous models (e.g. CV89), Hogg and Gayen (2020, referred to as HG20 hereafter) show that double gyres can be produced by buoyancy forcing alone. However, their use of large vertical diffusivity (up to $2 \times 10^{-3} \mathrm{~m}^{2} / \mathrm{s}$ ) in the upper ocean might unduly augment the role of buoyancy forcing.

Besides the direct effects of wind and buoyancy forcing, nonlinear processes such as mesoscale eddies also play key roles in the upper ocean circulation. Numerical studies have demonstrated that eddy mixing could homogenize the macroscopic potential vorticity (Rhines and Young 1982; Cox 1985), modify the shape of the main thermocline in the subtropical gyre (Henning and Vallis 2004), and strengthen the western boundary current extension (Lévy et al. 2010; Chassignet and Xu 2017). However, most studies have focused on the subtropical gyre, and little attention has been paid to whether the eddy mixing can affect the formation of the subpolar gyre for which there is a huge difference between CV89 and HG20.

Here we carry out a series of numerical experiments with varied forcing conditions, to investigate the dependence of the gyre circulations on the buoyancy and wind forcing, to contrast the laminar and eddy-resolving solutions, and to assess their sensitivity to the vertical diffusivity in a closed basin.

\section{Methods}

In this study, the MITgcm (Marshall et al. 1997) is configured in an idealized one-hemisphere ocean domain spanning $40^{\circ}$ in longitude and $60^{\circ}$ in latitude, bounded to the south by the equator. Two horizontal sphericalgrid resolutions of $1^{\circ}$ and $0.1^{\circ}$ are used to represent the non-eddy and eddy-resolving conditions, respectively. In the vertical, $29 z$-coordinate levels are set up in a 4000-m deep basin. The four lateral boundaries are all insulated, with no mass exchange across them. As in Liu et al. (2019), the model uses a linear equation of state that only depends on temperature, and salinity is kept constant at 35 PSU for simplicity.

The model is forced by zonally uniform wind stress and surface temperature restoration, as shown in Fig. $1 \mathrm{a}$ and $\mathrm{b}$. The reference wind stress profile is similar to that used in HG20, with the maximum eastward wind located at $38^{\circ} \mathrm{N}$. Three wind scenarios, no wind (W0), reference wind (W1), and double wind (W2), are configured to examine the contribution of the wind forcing. Following Bire and Wolfe (2018), a meridional gradient of buoyancy forcing from $10^{\circ} \mathrm{N}$ to $50^{\circ} \mathrm{N}$ is prescribed to facilitate the generation of eddies in the basin. The strength of the buoyancy forcing is varied by changing the restoration coefficient $\gamma$, with values of 0 (no buoyancy), $0.1 \mathrm{~m} /$ day (reference buoyancy), and $0.2 \mathrm{~m} /$ day (double buoyancy) being employed.

The model is initially spun-up by the buoyancy forcing $(\gamma=0.1 \mathrm{~m} /$ day $)$ alone for 1000 years to reach full equilibrium at $1^{\circ}$ resolution, after which all experiments are integrated for another 100 years. In $1^{\circ}$ simulations, the horizontal momentum dissipation is provided by a Laplacian viscosity with a coefficient of $A_{h}=2 \times 10^{4} \mathrm{~m}^{2} / \mathrm{s}$, and the lateral heat diffusivity $\kappa_{h}$ is set to $1 \times 10^{3} \mathrm{~m}^{2} / \mathrm{s}$. In $0.1^{\circ}$ simulations, the horizontal dissipation is calculated according to the velocity gradient based on the modified Leith biharmonic scheme (Fox-Kemper and Menemenlis 2008), and the lateral heat diffusivity is set to 0 . For all simulations, the vertical diffusivity is provided by the sum of a uniform background value $\kappa_{v}$ and that of the K-profile parameterization (KPP, Large et al. 1994). Vertical mixing exerts a significant control on the cold water subduction at high latitudes, with stronger mixing causing a stronger meridional overturning circulation (MOC, Jayne 2009; Jones and Abernathey 2019). HG20 uses a large vertical diffusivity (up to $2 \times 10^{-3} \mathrm{~m}^{2} / \mathrm{s}$ ) as a crude parameterization for the mixed layer turbulence. In our model, two vertical mixing scenarios with small $\left(\kappa_{v}=1 \times 10^{-5} \mathrm{~m}^{2} / \mathrm{s}\right)$ and large $\left(\kappa_{v}=1 \times 10^{-3} \mathrm{~m}^{2} / \mathrm{s}\right)$ diffusivity values are compared to examine their effects on the upper ocean gyres.

As listed in Table 1, a total of 32 model experiments are carried out. They are divided into four groups of differing combinations of horizontal resolution and vertical diffusivity, within each group eight different forcing conditions are used. For example, the experiment in Group 1 driven by the reference buoyancy and the reference wind stress is labeled G1B1W1. The same labeling rule applies to the rest of the experiments. The instantaneous sea surface temperature (SST, Fig. 1c) and relative vorticity (Fig. 1d) from the experiment G2B1W1 show that the $0.1^{\circ}$ experiments have adequately resolved the mesoscale eddies. Unless otherwise stated, the results shown below 

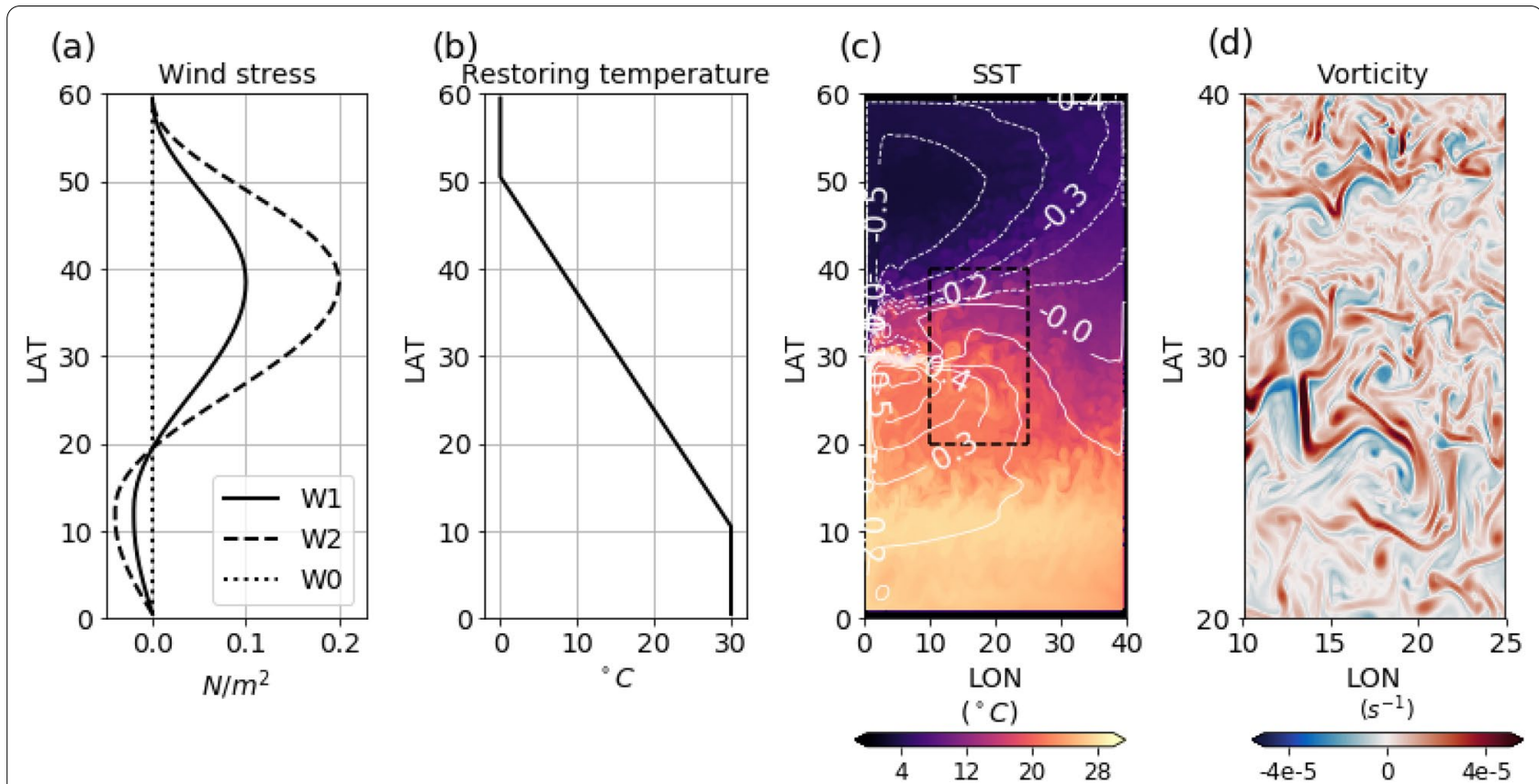

Fig. 1 Model forcing and selected results. a Wind stress, $\mathbf{b}$ restoring temperature profile, $\mathbf{c}$ instantaneous sea surface temperature (colors) and mean sea surface height (SSH, contours) from the experiment G2B1W1, and $\mathbf{d}$ instantaneous relative vorticity in the black-lined box in $\mathbf{c}$

Table 1 Expeiment setup

\begin{tabular}{|c|c|c|c|c|c|c|c|c|}
\hline & B1W0 & B2WO & BoW1 & B1W1 & B2W1 & BoW2 & B2W2 & B2W2 \\
\hline Wind & wo & Wo & W1 & W1 & W1 & W2 & W2 & W2 \\
\hline Buoyancy & $\gamma$ & $2 * \gamma$ & 0 & $\gamma$ & $2 * \gamma$ & 0 & $\gamma$ & $2 * \gamma$ \\
\hline Group 1 & \multicolumn{8}{|c|}{$1^{\circ} \& \mathbf{k}_{v}=1 \times 10^{-5} \mathrm{~m}^{2} / \mathrm{s}$} \\
\hline Group 2 & \multicolumn{8}{|c|}{$0.1^{\circ} \& \kappa_{v}=1 \times 10^{-5} \mathrm{~m}^{2} / \mathrm{s}$} \\
\hline Group 3 & \multicolumn{8}{|c|}{$1^{\circ} \& \kappa_{v}=1 \times 10^{-3} \mathrm{~m}^{2} / \mathrm{s}$} \\
\hline Group 4 & \multicolumn{8}{|c|}{$0.1^{\circ} \& \kappa_{v}=1 \times 10^{-3} \mathrm{~m}^{2} / \mathrm{s}$} \\
\hline
\end{tabular}

are the time-averaged fields over the last 50 years of each experiment.

\section{Results and discussion}

The mean sea surface height (SSH) from the simulations driven by wind alone, buoyancy alone, and both wind and buoyancy for three groups of experiments are shown in Fig. 2. When the buoyancy forcing is turned off (top panels), the SSH fields show double gyres generated by wind stress alone via the Sverdrup dynamics. These gyres have similar patterns in the non-eddy (Fig. 2a) and eddyresolving (Fig. 2b) experiments, but they are intensified in the latter case, especially over the subpolar region. The $\mathrm{SSH}$ fields are completely different when only buoyancy forcing is applied (middle panels). Unlike the pattern in HG20, there are no obvious double gyres in all three cases, and the decreasing SSH with latitude in the northern half of the basin indicates that the upper geostrophic current moves eastward. This circulation pattern has also been noticed by Colin de Verdière (1988) and Gjermundsen et al. (2018), and their results show that the surface eastward flow is balanced by a westward returning flow at depth in the subpolar region, suggesting that there is no barotropic flow with only buoyancy forcing in a flatbottom basin.

When the model is driven by both wind and buoyancy forcing, the coarse-grid case with small vertical diffusivity (Fig. 2g) shows an expected subtropical gyre and a broad eastward flow in the subpolar region. This indicates that the wind-driven subpolar gyre is overtaken by the buoyancy-driven eastward current, as also seen in CV89. The barotropic streamfunction in the 

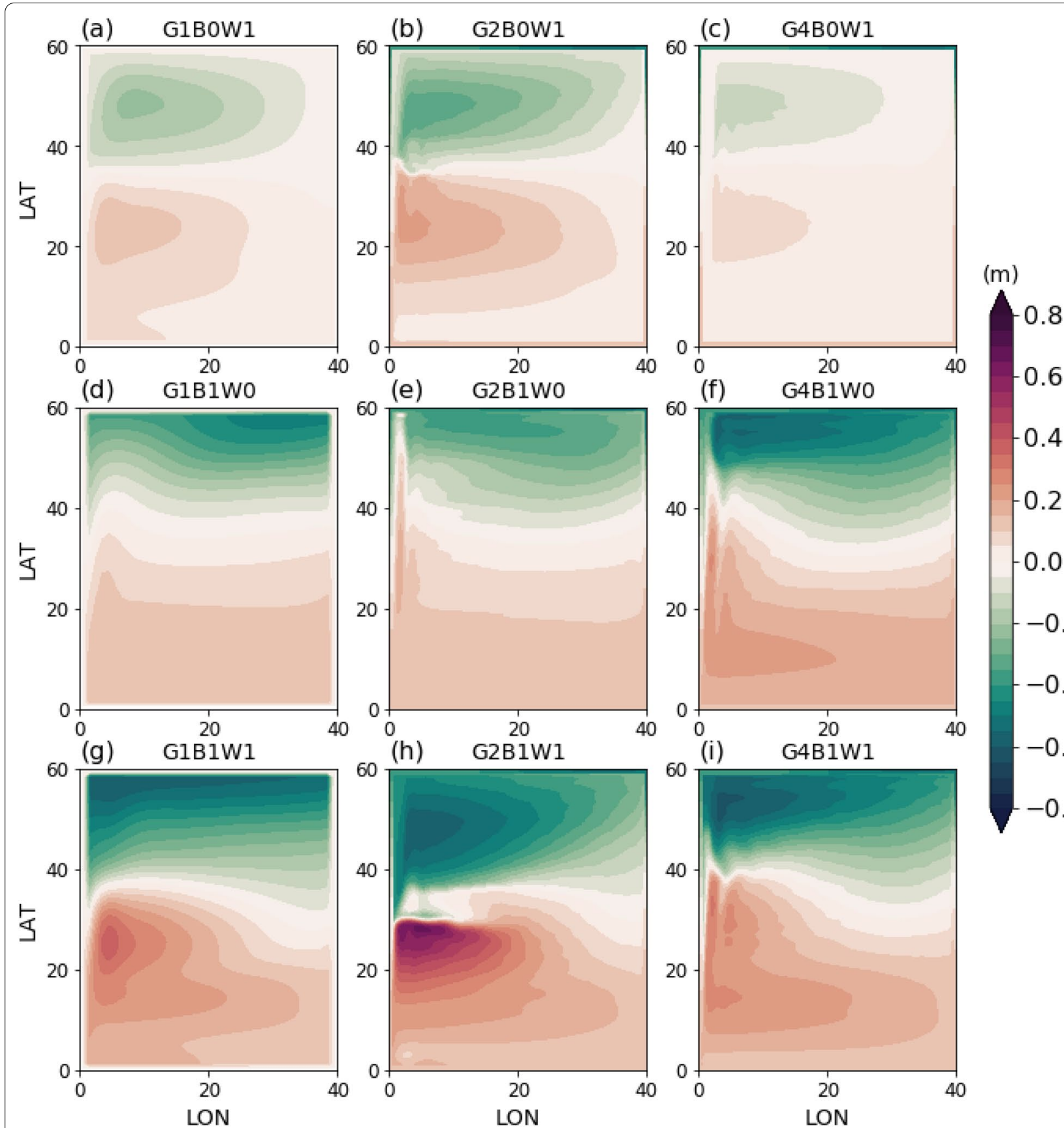

Fig. $2 \mathrm{SSH}$ fields for selected experiments. The top, middle, and bottom panels correspond to the three different forcing conditions. The three columns correspond to the three groups with different combinations of horizontal resolution and vertical diffusivity

subpolar region should exhibit a distinct cyclonic gyre that satisfies the Sverdrup dynamics, which, however, would not manifest in the SSH field. This is because the $\mathrm{SSH}$, as a product of the vertical stratification and the thermocline depth, mainly captures the signal of the first baroclinic mode. These results suggest that the buoyancy forcing produces a broad eastward flow in the subpolar region, obscuring the barotropic wind-driven subpolar gyre. Interestingly, the SSH field shows a distinct subpolar gyre in the eddy-resolving case (Fig. 2h), which has to be the result of the active eddy mixing because the horizontal resolution is the only parameter that has been varied. From the right columns of Fig. 2, it is clearly seen that increasing the vertical diffusivity 
tends to weaken the wind-driven gyres and strengthen the buoyancy-driven circulation.

The zonally averaged zonal velocity and temperature from selected experiments are shown in Fig. 3a and b. In G1B1W1, the eastward flow in the subpolar region extends to more than $500 \mathrm{~m}$ in the vertical, below which the westward flow extends to about $2500 \mathrm{~m}$. In G2B1W1, significant eastward and westward flows are confined to the upper $500 \mathrm{~m}$ with no zonal overturning circulation at high latitudes, aside from the banded features resulting from the residual effects of eddies. The surface temperature of the non-eddy case reflects the restoring temperature profile (Fig. 1b), with a strong meridional gradient in the subpolar region where deep convection is active. The cold water sinks due to its higher density, and the mixed layer deepens to more than $1000 \mathrm{~m}$ near the northern boundary. The temperature gradient requires the geostrophic current to be predominantly zonal and directed to the east. In the eddy-resolving case, however, the subpolar water temperature above $500 \mathrm{~m}$ is greatly homogenized, with a value about $4{ }^{\circ} \mathrm{C}$ to $6{ }^{\circ} \mathrm{C}$ (Fig. 3c). Compared with G1B1W1, the temperature field from G2B1W1 is much closer to the WOCE observation along $179^{\circ} \mathrm{E}$ (see Additional file 1: Fig. S1, Talley 2007), although our model is highly idealized.

The vertical and zonal means of the temperature above $500 \mathrm{~m}$ for these two cases are shown in Fig. 3c. With the model resolution increasing from $1^{\circ}$ to $0.1^{\circ}$, the meridional temperature range in the subpolar region decreases from about $6{ }^{\circ} \mathrm{C}$ to $2{ }^{\circ} \mathrm{C}$, which means that the eddy mixing reduces the meridional temperature gradient by about $66.7 \%$. The time-mean meridional heat transport in the eddying case is composed of mean advection and eddy flux as follows (Cox 1985)

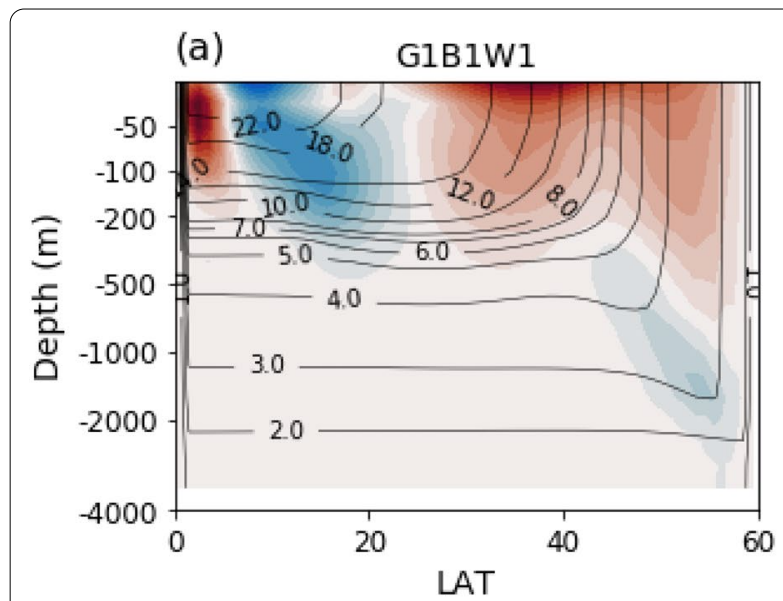

(c)
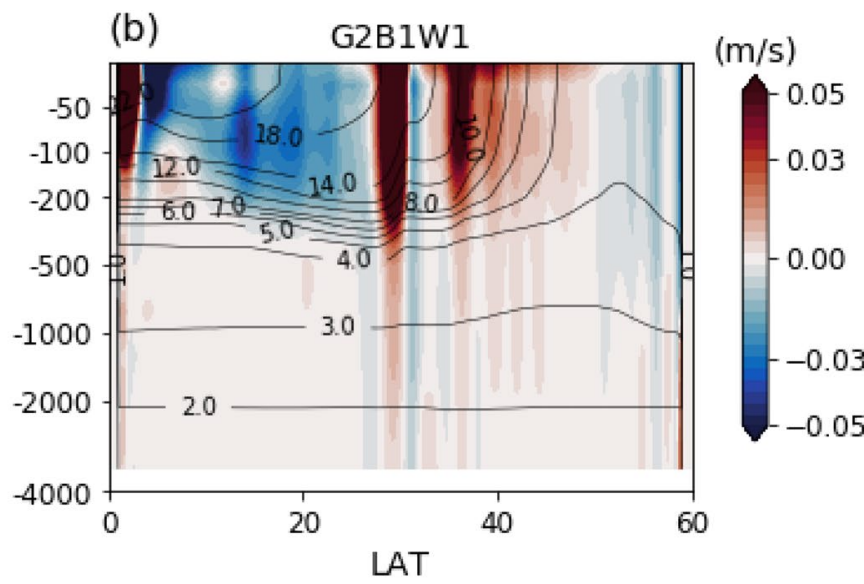

(d)
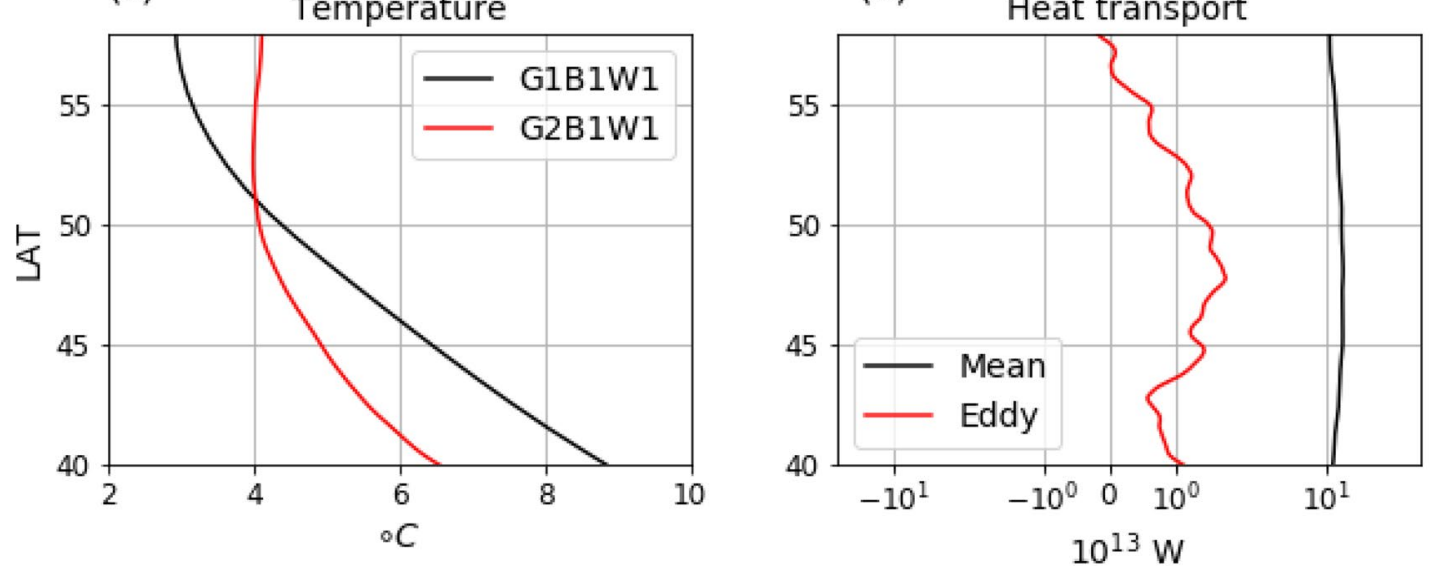

Fig. 3 The zonally averaged zonal velocity (colors) and temperature (contours) from experiments a G1B1W1 and b G2B1W1. c The zonally and vertically averaged temperature above $500 \mathrm{~m}$ in the subpolar region for the two experiments. $\mathbf{d}$ The zonally and vertically integrated northward heat transport above $500 \mathrm{~m}$ by the mean flow and eddies for G2B1W1 


$$
Q=\bar{Q}+Q^{\prime}=\int_{\mathrm{y} 1}^{\mathrm{y} 2} \int_{-\mathrm{H}}^{0} C_{p} \rho_{0} \bar{v} \bar{T} \mathrm{~d} z \mathrm{~d} y+\int_{\mathrm{y} 1}^{\mathrm{y} 2} \int_{-\mathrm{H}}^{0} C_{p} \rho_{0} \overline{v^{\prime} T^{\prime}} \mathrm{d} z \mathrm{~d} y,
$$

where the bar and prime represent the time-mean and perturbation, respectively, $C_{p}=4 \times 10^{3} \mathrm{~J} /\left(\mathrm{kg} \cdot{ }^{\circ} \mathrm{C}\right)$ is the ocean heat capacity, and $\rho_{0}=1.025 \times 10^{3} \mathrm{~kg} / \mathrm{m}^{3}$ is the reference density. This calculation is based on high-frequency ( 5 days) outputs over the last 10 years of the model run. Mean-advection and eddy-flux terms in Eq. (1) from G2B1W1 are calculated above $500 \mathrm{~m}$ (Fig. 3d), and it shows that the eddy heat transport from $40^{\circ} \mathrm{N}$ to $55^{\circ} \mathrm{N}$ accounts for about $10 \%$ of that induced by the mean flow, which is in agreement with the estimate of Bryan (1996). These results suggest that the northward eddy heat transport warms up the subpolar upper ocean, reducing the meridional temperature gradient and the associated eastward flow caused by the buoyancy forcing. Similar features are observed in the experiments with large vertical diffusivity as well (see Additional file 1: Fig. S2). Therefore, eddy mixing plays a crucial role in maintaining the wind-driven subpolar gyre.

We now investigate the dependence of the subtropical and subpolar gyres on the external forcing in terms of streamfunction. Following HG20, the subtropical gyre is defined as the integrated volume transport above the main thermocline $\left(10{ }^{\circ} \mathrm{C}\right.$ isotherm) that is close to the zero wind stress curl latitude in G2B1W1. The maximum values at $10^{\circ} \mathrm{E}$ of the subtropical streamfunction are taken to represent the strength of the subtropical gyre. Figure 4 shows the dependence of subtropical and subpolar gyres on the wind and buoyancy forcing for both small and large vertical diffusivity. For both small and large vertical diffusivity (Fig. 4a and b), the enhancement of the subtropical gyre is prominent from no-buoyancy to reference buoyancy cases. This is because, in the zerobuoyancy case, there is no main thermocline to support a subtropical gyre. When the buoyancy forcing increases from reference to double cases, small and large vertical diffusivity simulations have significant differences. The gyre strength is dependent more on the wind forcing in the low-diffusivity experiments and on the buoyancy forcing in the large-diffusivity experiments. The strong vertical mixing produces a strong MOC and pushes the isotherms downward and northward (see Additional file 1: Fig. S3), making the subtropical gyre increase with the buoyancy forcing even without wind input. However, such a large vertical diffusivity is not realistic in the real ocean, since the directly observed value in most of the ocean is about $1 \times 10^{-5} \mathrm{~m}^{2} / \mathrm{s}$ (Talley et al. 2011). Using a large vertical diffusivity may overestimate the roles of buoyancy forcing in the subtropical gyre and it should be treated carefully in a closed basin simulation.
Additionally, from non-eddy to eddy-resolving simulations, the relative contributions of the buoyancy and wind forcing are not dramatically changed, but eddy mixing strengthens the subtropical gyre by about 5-10 Sv for each experiment.

Due to the outcrop of the main thermocline around the subtropical front, we calculate the streamfunction above $500 \mathrm{~m}$ for the subpolar gyre and use the minimum values along $10^{\circ} \mathrm{E}$ to represent the gyre strength. Unlike the subtropical gyre, the dependence of the subpolar gyre on the wind and buoyancy forcing is not very sensitive to the vertical diffusivity, but huge differences exist between non-eddy and eddy-resolving experiments. The eddy mixing removes the eastward upper-level flow (and the associated westward returning flow) driven by the buoyancy loss, thus the subtropical gyre reappears and its strength increases almost linearly with the wind forcing.

\section{Conclusions}

Classic circulation theories based on the Sverdrup balance have been challenged by modern observations, and previous models have noted the significant roles of buoyancy flux (Gjermundsen et al. 2018) and eddy mixing (Lévy et al. 2010) in the large-scale circulation. However, the relative importance of the buoyancy and wind forcing for upper ocean gyres is still unclear, and there are obvious conflicts between CV89 and HG20 over the solution in the subpolar region. In this study, a series of numerical simulations with different forcing conditions are conducted to compare non-eddy and eddy-resolving solutions, to investigate the contributions of the wind and buoyancy forcing, and to examine the sensitivity of the resulting ocean gyres on the vertical diffusivity.

The non-eddy solution driven by the buoyancy forcing produces a broad geostrophic eastward flow extending to the northern basin boundary, which is particularly strong in the subpolar region and thus overtakes the wind-driven cyclonic gyre there. However, the northward heat transport by eddies homogenizes the subpolar water, reducing the meridional temperature gradient by about $66.7 \%$, allowing the subpolar gyre to reemerge, which suggests that the eddies play a significant role in maintaining the subpolar gyre. On the other hand, the strength of the subtropical gyre is reinforced by the eddying regime, and it is quite sensitive to the choice of the vertical diffusivity.

Based on the buoyancy-driven simulation in a northern hemisphere basin, Bire and Wolfe (2018) demonstrate that the eddy form drag can drive and maintain an eastern boundary current, thus producing a relatively weak subpolar gyre (their Fig. 4). Their model fails to generate a subtropical gyre without wind using a vertical diffusivity $1 \times 10^{-4} \mathrm{~m}^{2} / \mathrm{s}$, which is quite similar 


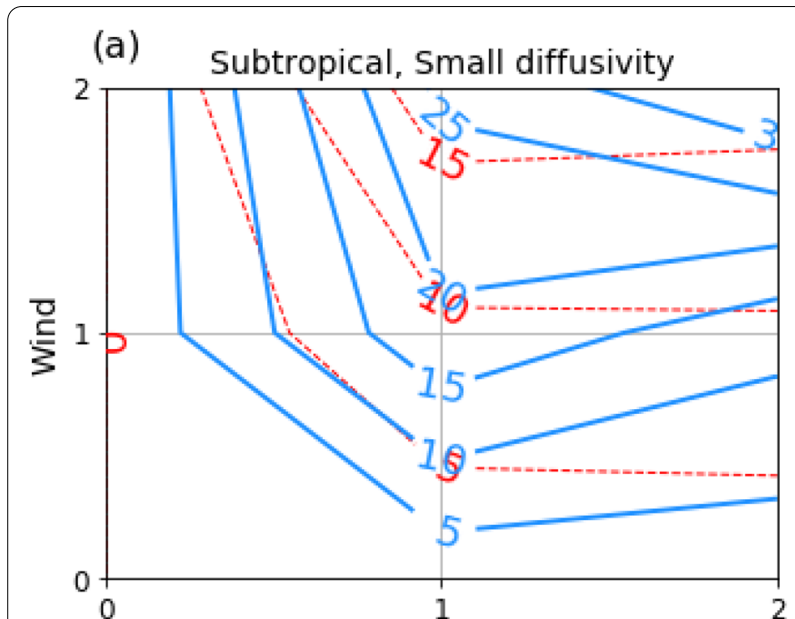

(c)

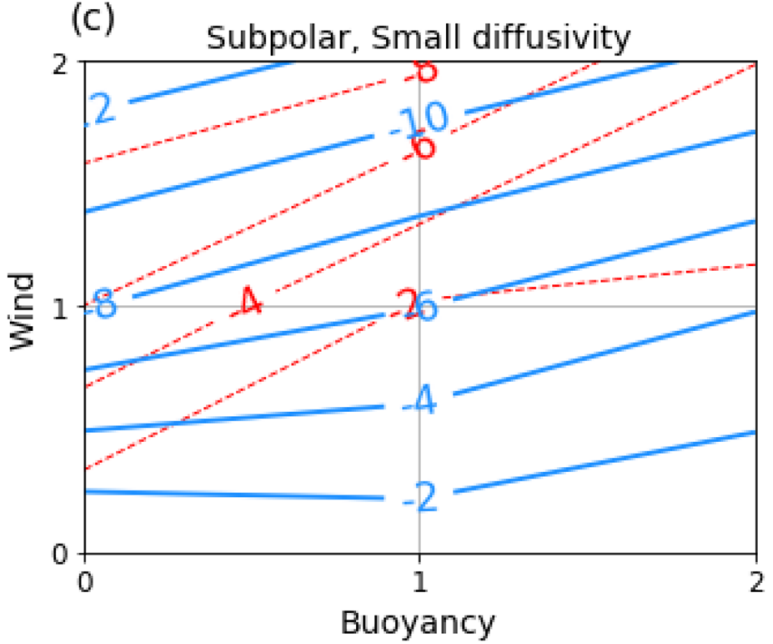

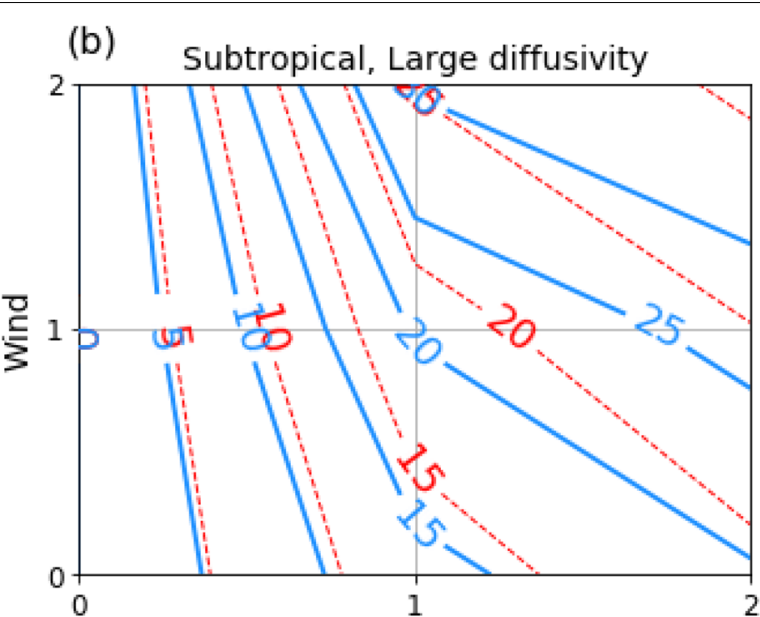

(d)

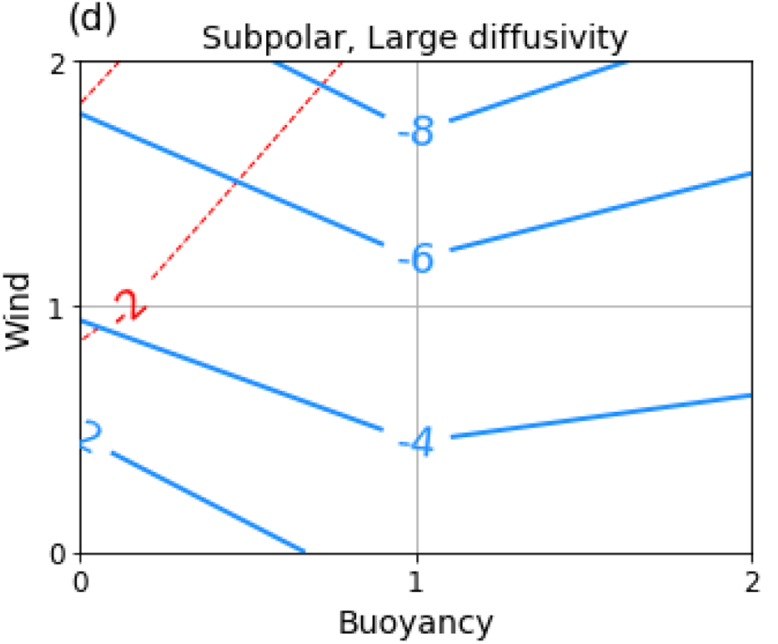

Fig. 4 The dependence of $\mathbf{a}$, $\mathbf{b}$ subtropical and $\mathbf{c}$, $\mathbf{d}$ subpolar gyres on the wind and buoyancy forcing for both small and large vertical diffusivity. Contours represent the strength of gyres in different experiments, with red and blue contours representing the non-eddy and eddy-resolving solutions, respectively. Values of 0,1 , and 2 in the buoyancy (wind) axis represent no-buoyancy (wind), reference, and double-buoyancy (wind) cases (listed in Table 1), respectively

to our experiment G2B1W0 (Fig. 2e). The generation of the subtropical gyre without wind forcing in G4B1W0 (about $15 \mathrm{~Sv}$ ) and HG20 can be attributed to the unrealistic MOC forced by the strong diapycnal mixing in a closed basin, and it may overestimate the role of buoyancy forcing in driving the subtropical gyre. As the connection between the MOC and the upper ocean gyres is important, further study should be carried out in a multi-basin model that simulates the full structure of the MOC. Admittedly, while a total of 32 experiments have been carried out in this study, only three scenarios of wind and buoyancy forcing are considered. Even with this limitation, our results nonetheless firmly establish the essential roles played by wind and buoyancy forcing, as well as eddy mixing, in driving the upper ocean gyres. A theory lacking any of them is necessarily incomplete to describe the observed circulations.

\section{Supplementary Information}

The online version contains supplementary material available at https://doi. org/10.1186/s40562-022-00213-2.

Additional file 1. Additional figures.

\section{Acknowledgements}

All computations and analysis are implemented on the Tianhe-2 supercomputer.

\section{Authors' contributions}

$T L$ and $\mathrm{HO}$ proposed the topic and designed this study. TL and XL performed the numerical simulation and all data analysis. TL wrote the original manuscript. $\mathrm{HO}, \mathrm{YQ}$, and DC contributed to reviewing and editing the manuscript. 
All authors discussed and contributed to the manuscript revision. All authors read and approved the final manuscript.

\section{Funding}

T. Liu, X. Liu, Y. Qian, and D. Chen are funded by the National Natural Science Foundation of China $(41730535,42106008)$, the China Postdoctoral Science Foundation (2020M681968), the Natural Science Foundation of Zhejiang Province (LY21D060001), and the National Natural Science Foundation of China (41976023). H. W. Ou is not supported by any external grants.

\section{Availability of data and materials}

This research is based on outputs from numerical models, and all code is available online (https://github.com/liutongya/wind_buo_circulation). No other open-source data is used in this study.

\section{Declarations}

\section{Competing interests}

The authors declare that they have no competing interests.

\section{Author details}

${ }^{1}$ State Key Laboratory of Satellite Ocean Environment Dynamics, Second Institute of Oceanography, Ministry of Natural Resources, Hangzhou, Zhejiang, China. ${ }^{2}$ Lamont-Doherty Earth Observatory, Columbia University, New York, NY, USA. ${ }^{3}$ Southern Marine Science and Engineering Guangdong Laboratory (Zhuhai), Zhuhai, China. ${ }^{4}$ State Key Laboratory of Tropical Oceanography, South China Sea Institute of Oceanology, Chinese Academy of Sciences, Guangzhou, China.

Received: 12 December 2021 Accepted: 2 January 2022

Published online: 11 January 2022

\section{References}

Bire S, Wolfe CL (2018) The role of eddies in buoyancy-driven eastern boundary currents. J Phys Oceanogr 48(12):2829-2850. https://doi.org/10.1175/ JPO-D-18-0040.1

Bryan K (1996) The role of mesoscale eddies in the poleward transport of heat by the oceans: a review. Physica D 98(2-4):249-257. https://doi.org/10. 1016/0167-2789(96)00119-4

Chassignet EP, Xu X (2017) Impact of horizontal resolution (1/12 to 1/50) on Gulf Stream separation, penetration, and variability. J Phys Oceanogr 47(8):1999-2021. https://doi.org/10.1175/JPO-D-17-0031.1

Colin de Verdière A (1988) Buoyancy driven planetary flows. J Mar Res 46(2):215-265. https://doi.org/10.1357/002224088785113667

Colin de Verdière A (1989) On the interaction of wind and buoyancy driven gyres. J Mar Res 47(3):595-633. https://doi.org/10.1357/0022240897 85076172

Colin de Verdière A, Ollitrault M (2016) A direct determination of the World Ocean barotropic circulation. J Phys Oceanogr 46(1):255-273. https://doi. org/10.1175/JPO-D-15-0046.1

Cox MD (1985) An eddy resolving numerical model of the ventilated thermocline. J Phys Oceanogr 15(10):1312-1324. https://doi.org/10.1175/15200485(1985)015\%3c1312:AERNMO\%3e2.0.CO;2

Ferrari R, Wunsch C (2009) Ocean circulation kinetic energy: reservoirs, sources, and sinks. Annu Rev Fluid Mech. https://doi.org/10.1146/annurev.fluid.40. 111406.102139

Fox-Kemper B, Menemenlis D (2008) Can large eddy simulation techniques improve mesoscale rich ocean models. Ocean Model Eddying Regime 177:319-337. https://doi.org/10.1029/177GM19

Ganachaud A, Wunsch C (2000) Improved estimates of global ocean circulation, heat transport and mixing from hydrographic data. Nature 408(6811):453-457. https://doi.org/10.1038/35044048

Gjermundsen A, LaCasce JH, Denstad L (2018) The thermally driven ocean circulation with realistic bathymetry. J Phys Oceanogr 48(3):647-665. https://doi.org/10.1175/JPO-D-17-0147.1

Gray AR, Riser SC (2014) A global analysis of Sverdrup balance using absolute geostrophic velocities from Argo. J Phys Oceanogr 44(4):1213-1229. https://doi.org/10.1175/JPO-D-12-0206.1
Henning CC, Vallis GK (2004) The effects of mesoscale eddies on the main subtropical thermocline. J Phys Oceanogr 34(11):2428-2443. https://doi. org/10.1175/JPO2639.1

Hogg AM, Gayen B (2020) Ocean gyres driven by surface buoyancy forcing. Geophys Res Lett 47(16): e2020GL088539. https://doi.org/10.1029/2020G L088539.

Jayne SR (2009) The impact of abyssal mixing parameterizations in an ocean general circulation model. J Phys Oceanogr 39(7):1756-1775. https://doi. org/10.1175/2009JPO4085.1

Jones CS, Abernathey RP (2019) Isopycnal mixing controls deep ocean ventilation. Geophys Res Lett 46(22):13144-13151. https://doi.org/10.1029/ 2019GL085208

Large WG, McWilliams JC, Doney SC (1994) Oceanic vertical mixing: a review and a model with a nonlocal boundary layer parameterization. Rev Geophys 32(4):363-403. https://doi.org/10.1029/94RG01872

Lévy M, Klein P, Tréguier AM, lovino D, Madec G, Masson S, Takahashi K (2010) Modifications of gyre circulation by sub-mesoscale physics. Ocean Model 34(1-2):1-15. https://doi.org/10.1016/j.ocemod.2010.04.001

Liu T, Abernathey R, Sinha A, Chen D (2019) Quantifying Eulerian Eddy leakiness in an idealized model. J Geophys Res 124(12):8869-8886. https://doi. org/10.1029/2019JC015576

Luyten JR, Pedlosky J, Stommel H (1983) The ventilated thermocline. J Phys Oceanogr 13(2):292-309. https://doi.org/10.1175/1520-0485(1983)013\% 3c0292:TVT\%3e2.0.CO;2

Marshall J, Adcroft A, Hill C, Perelman L, Heisey C (1997) A finite-volume, incompressible Navier Stokes model for studies of the ocean on parallel computers. J Geophys Res 102(C3):5753-5766. https://doi.org/10.1029/ 96JC02775

Munk WH (1950) On the wind-driven ocean circulation. J Atmos Sci 7(2):80-93. https://doi.org/10.1175/1520-0469(1950)007\%3c0080:OTWDOC\%3e2.0. $\mathrm{CO} ; 2$

Qiu B, Chen S (2010) Interannual variability of the North Pacific Subtropical Countercurrent and its associated mesoscale eddy field. J Phys Oceanogr 40(1):213-225. https://doi.org/10.1175/2009JPO4285.1

Rhines PB, Young WR (1982) Homogenization of potential vorticity in planetary gyres. J Fluid Mech 122:347-367. https://doi.org/10.1017/S002211208 2002250

Samelson RM, Vallis GK (1997) Large-scale circulation with small diapycnal diffusion: the two-thermocline limit. J Mar Res 55(2):223-275. https://doi. org/10.1357/0022240973224382

Stewart AL, Ferrari R, Thompson AF (2014) On the importance of surface forcing in conceptual models of the deep ocean. J Phys Oceanogr 44(3):891-899. https://doi.org/10.1175/JPO-D-13-0206.1

Stommel HM (1948) The westward intensification of wind-driven ocean currents. EOS Trans Am Geophys Union 29(2):202-206. https://doi.org/10. 1029/TR029i002p00202

Stommel HM (1965) The Gulf Stream: a physical and dynamical description. Univ of California Press. https://doi.org/10.1002/qj.49709239127

Sverdrup HU (1947) Wind-driven currents in a baroclinic ocean; with application to the equatorial currents of the eastern Pacific. Proc Natl Acad Sci USA 33(11):318. https://doi.org/10.1073/pnas.33.11.318

Talley LD (2007) Hydrographic atlas of the world ocean circulation experiment (WOCE): volume 2: Pacific Ocean. Southampton: WOCE International Project Office. https://doi.org/10.21976/C6WC77.

Talley LD, Pickard GL, Emery WJ, Swift JH (2011) Dynamical processes for descriptive ocean circulation. Descr Phys Oceanogr. https://doi.org/10. 1016/C2009-0-24322-4

Vallis GK (2000) Large-scale circulation and production of stratification: effects of wind, geometry, and diffusion. J Phys Oceanogr 30(5):933-954. https:// doi.org/10.1175/1520-0485(2000)030\%3c0933:LSCAPO\%3e2.0.CO;2

\section{Publisher's Note}

Springer Nature remains neutral with regard to jurisdictional claims in published maps and institutional affiliations. 